\title{
Diferenças fenológicas e produtivas de variedades de mangaba
}

A mangabeira é uma espécie com potencial para domesticação e produção comercial, mas a grande variação encontrada nas plantas nativas requer maior conhecimento para direcionar o seu uso e exploração. Neste contexto, esse estudo busca analisar as variedades de Hancornia speciosa de um banco de germoplasma, quanto às características de fenologia, frutos, sementes e desenvolvimento inicial. A pesquisa foi realizada em 2018, no Banco de germoplasma da Escola de Agronomia da Universidade Federal de Goiás, com progênies de 28 populações nativas, com 14 anos, abrangendo as subespécies pubescens, gardneri, speciosa e cuyabensis. Os dados analisados foram de fenologia, caracterizando a folhação, floração, brotações novas e frutificação. Caracterização de frutos e sementes, além do desenvolvimento inicial de mudas. A floração foi à fase de maior diferenciação entre as variedades, sendo a speciosa com maior florescimento no período. As variedades cuyabensis e gardneri se mostraram próximas fenologicamente enquanto a pubescens mostrou ausência de floração e frutificação no período. As variedades cuyabensis e gardneri se mostraram próximas também quanto à caracterização dos frutos e sementes, enquanto speciosa foi a mais distante. Essa última apresentou maior diâmetro de frutos, além de maior número e massa de sementes. Quanto à massa de frutos as variedades cuyabensis e gardneri foram superiores. O desenvolvimento inicial foi distinto apenas para speciosa, que apresentou maior altura, diâmetro e número de par de folhas.

Palavras-chave: Hancornia speciosa; Cerrado; Frutos nativos; Banco de germoplasma.

\section{Phenological and productive differences in mangaba varieties}

He mangabeira is a species with potential for domestication and commercial production, but the great variation found in native plants requires greater knowledge to direct its use and exploration. In this context, this study seeks to analyze the varieties of Hancornia speciosa from a germplasm bank, regarding the characteristics of phenology, fruits, seeds and initial development. The research was carried out in 2018, at the Germplasm Bank of the School of Agronomy of the Federal University of Goiás, with progenies of 28 native populations, aged 14, covering the subspecies pubescens, gardneri, speciosa and cuyabensis. The analyzed data were of phenology, characterizing the foliage, flowering, new shoots and fruiting. Characterization of fruits and seeds, in addition to the initial development of seedlings. Flowering was the stage of greatest differentiation between varieties, being the speciosa with the highest flowering in the period. The varieties cuyabensis and gardneri showed to be close phenologically while the pubescens showed absence of flowering and fruiting in the period. The cuyabensis and gardneri varieties were also close in terms of fruit and seed characterization, while speciosa was the most distant. The latter showed a larger diameter of fruits, in addition to a greater number and mass of seeds. As for the mass of fruits, the varieties cuyabensis and gardneri were superior. The initial development was different only for speciosa, which presented greater height, diameter and number of leaf pairs.

Keywords: Hancornia speciose; Cerrado; Native fruits; Germplasm bank.

Topic: Melhoramento e Recursos Genéticos

Reviewed anonymously in the process of blind peer
Received: 02/08/2020

Approved: 18/09/2020
Charlismilã Amorim do Couto (iD)

Universidade Federal de Goiás, Brasil

http://lattes.cnpq.br/3843160055311655

http://orcid.org/0000-0003-0164-0424

charliscouto@hotmail.com

Muza do Carmo Vieira (iD)

Instituto Federal Goiano, Brasil

http://lattes.cnpq.br/3892400622755069

http://orcid.org/0000-0003-1730-9541

mcvmuza@gmail.com

Eli Regina Barbosa de Souza (iD

Universidade Federal de Goiás, Brasil

http://lattes.cnpq.br/7641431808466123

http://orcid.org/0000-0001-6225-6122

eliregina1@gmail.com

\author{
Rommel Bernardes da Costa (iD \\ Universidade Federal de Goiás, Brasil \\ http://lattes.cnpq.br/8037012195949903 \\ http://orcid.org/0000-0002-8166-6829 \\ rommelbc@gmail.com \\ Paulo Alcanfor Ximenes (ic \\ Universidade Federal de Goiás, Brasil \\ http://lattes.cnpq.br/4885283657209694 \\ http://orcid.org/0000-0002-4525-8377 \\ pauloalcanfor@gmail.com \\ Patrícia Pinheiro da Cunha (iD \\ Universidade Federal de Goiás, Brasil \\ http://lattes.cnpq.br/3825602431744625 \\ http://orcid.org/0000-0002-7394-311X \\ ppcunhafeliz@gmail.com
}

Referencing this:

COUTO, C. A.; VIEIRA, M. C.; SOUZA, E. R. B.; COSTA, R. B.; XIMENES, P. A.; CUNHA, P. P.. Diferenças fenológicas e produtivas de variedades de mangaba. Revista Ibero Americana de Ciências Ambientais, v.11, n.5, p.90-98, 2020. DOI: http://doi.org/10.6008/CBPC2179$\underline{6858.2020 .005 .0010}$

DOI: 10.6008/CBPC2179-6858.2020.005.0010 


\section{INTRODUÇÃO}

O Brasil é um dos países com maior biodiversidade e um dos principais centros de diversidade genética de espécies frutíferas conforme salienta Mittermeier et al. (1997). O Cerrado brasileiro se destaca pela biodiversidade de árvores frutíferas (SOARES et al., 2017), muitas delas com potencial de utilização agrícola (ALMEIDA et al., 2016).

Os frutos das espécies nativas do Cerrado apresentam, em geral, elevado valor nutricional, além de atrativos sensoriais como a cor, o sabor e o aroma peculiares e intensos. A exploração dos frutos dessas nativas é, geralmente, via extrativismo, gerando fonte de renda e favorecendo, principalmente a agricultura familiar, visto a comercialização local. A exploração comercial é pequena e restrita, mas pode ser mais explorada, visto que o consumo de frutas de espécies exóticas tem crescido no Brasil e outros países (AGOSTINI-COSTA et al., 2008; VIEIRA et al., 2010).

Uma das espécies frutíferas nativas do Cerrado com grande potencial de exploração comercial é a mangabeira (Hancornia speciosa Gomez), que predomina no Cerrado e na Caatinga (SOARES et al., 2007). A mangaba é um fruto com características sensoriais peculiares, como aroma e sabor, apropriado para o consumo in natura (FERREIRA et al., 1998), ou para o beneficiamento agroindustrial (ÁVILA et al., 2010; HANSEN et al., 2013).

Na visão de Almeida et al. (2018), Vieira Neto et al. (2002) algumas características dificultam a comercialização da mangada em larga escala e necessitam ser contornadas, como a relação entre alta demanda do mercado e o curto período de safra, além da alta perecibilidade dos frutos após o amadurecimento. A expansão comercial da mangaba necessita, portanto, encontrar plantas com período de produção de frutos mais longo, além da implantação de pomares comerciais para garantir maior quantidade de frutos do que a produção extrativista. Outros estudos acerca da pós-colheita, para aumentar a durabilidade e resistência dos frutos também se fazem necessários.

Os frutos de espécies nativas apresentam grande variação morfológica derivada, por exemplo, do local, da planta e da variedade, visto elevada biodiversidade natural, ideal para o melhoramento vegetal. Para a espécie Hancornia speciosa são aceitas seis variedades botânicas: var. speciosa; var. maximiliani; var. cuyabensis; var. lundii; var. gardneri e var. pubescens (MONACHINO, 1945).

Cada variedade apresenta características de fenologia, morfologia e produtividade distintas, e o seu conhecimento é fundamental para a exploração comercial da espécie. Inicialmente, o estudo da biologia das variedades, como dados fenológicos e de caracterização de frutos e semente são fundamentais para embasar a exploração comercial (BIANCO et al., 1986; FREITAS et al., 2002). Neste contexto, este estudo objetivou distinguir as variedades de Hancornia speciosa, no Banco de germoplasma da Escola de Agronomia da Universidade Federal de Goiás nas condições climáticas da região central do Estado de Goiás, quanto as características de fenologia, frutos, sementes e desenvolvimento inicial. 


\section{MATERIAIS E MÉTODOS}

O experimento foi conduzido em 2018, com plantas de mangabeira, originárias de plantas nativas amostradas no Cerrado e plantadas em 2005 no banco de germoplasma da Escola de Agronomia, na Universidade Federal de Goiás (Goiânia/GO; 16ำ35'12”'S; 4921'14”W; 730 m). O clima da região é do tipo Aw (Tropical quente e úmido), com inverno seco (KÖPPEN et al., 1928), apresentando médias anuais de 1.494 mm, com desvio médio de $187.6 \mathrm{~mm}$ (CASAROLI et al., 2018). O solo da área do experimento foi classificado como Latossolo Vermelho distrófico, de textura média e relevo suavemente ondulado (EMBRAPA, 2013).

Os tratamentos foram constituídos por quatro matrizes do banco de germoplasma, para cada subespécie botânica de Hancornia speciosa Gomez, pubescens, gardneri, speciosa e cuyabensis. As coletas dos dados foram realizadas entre agosto a dezembro 2018 e de janeiro a dezembro de 2019. A fenologia foi mensurada considerando a observação da produção de frutos em mais de 50\% da projeção da copa, e utilizando uma escala de 0 a 10 para caracterizar a folhação, floração, brotações novas e frutificação. Essa escala considera que, em relação ao total da copa da planta, a ocorrência pode ser de: 0 = ausência do fenômeno, 1 = 10\%, 2 = 20\%, 3 = 30\%, 4 = 40\%, $5=50 \%, 6=60 \%, 7=70 \%, 8=80 \%, 9=90 \%$ e $10=100 \%$ [metodologia adaptada de Ribeiro et al. (1986)].

A caracterização de frutos e sementes foi realizada com a coleta de 20 frutos por matriz, totalizando 80 frutos. Cada fruto foi caracterizado quanto a massa fresca (MF), com uso de balança analítica com 0,001 g de precisão, diâmetro transversal (DT) e longitudinal (DL), com paquímetro digital de precisão de 0,01 mm. Para a caracterização das sementes, os frutos foram macerados e colocados em hidróxido de amônio a 1,5\% por 48 horas, para retirada do excesso de polpa. As sementes foram verificadas quanto ao número e a massa (g) fresca e seca (as sementes foram colocadas para secar em papel toalha por seis horas).

As sementes ficaram armazenadas por oito dias em geladeira ( $8^{\circ} \mathrm{C}$ ) e posteriormente foi realizada a semeadura em bandejas de isopor de 128 células com substrato Biolplant. As bandejas foram dispostas em casa de vegetação com sombrite de $50 \%$ e irrigação por aspersão realizada duas vezes ao dia. 0 desenvolvimento das mudas foi verificado aos 31 e 67 dias após a semeadura (DAS), com os dados de comprimento da planta (da raiz até a altura da última folha $(\mathrm{cm})$ ), número de par de folhas e diâmetro do caule $(\mathrm{mm})$.

Os dados de fenologia de plantas, biometria de frutos e sementes, e desenvolvimento de mudas de mangaba foram submetidos à análise multivariada de variância (MANOVA). Após evidenciar diferenças entre os grupos, aplicou-se um gráfico biplot com as duas primeiras variáveis canônicas, para analisar diferenças multivariadas entre tratamentos com o auxílio de elipses de $95 \%$ de confianças para os escores médios. As análises estatísticas foram realizadas com o software R versão 3.5.3 (R CORE TEAM, 2019).

\section{RESULTADOS}

Quanto às fases fenológicas todas as espécies de mangaba se diferenciaram estatisticamente (Figura 2). Na fase de floração a subespécie speciosa foi a que apresentou maior nota $(8,00)$, enquanto a variedade 
cuyabensis apresentou maior índice de folhação (8.20). As variedades cuyabensis e gardneri se mostraram próximas, principalmente quanto à folhação. A variedade pubescens se mostrou mais distante, influência provável da ausência de floração e frutificação no período analisado. A variável que mais diferenciou as espécies foi o índice de floração, representada no gráfico como o maior vetor.

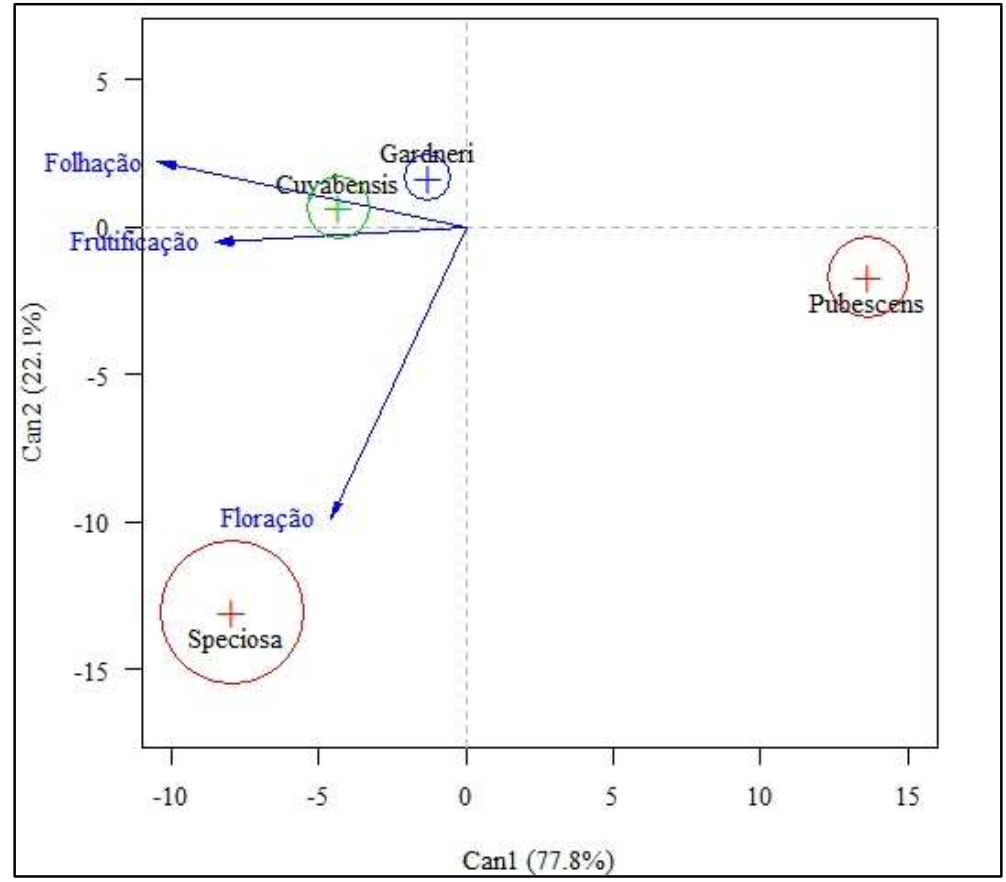

Figura 1: Dispersão gráfica de quatro variedades botânicas de mangabeira (var. speciosa, cuyabensis, gardneri e pubescens) da Coleção de Germoplasma da EA/UFG, classificadas por análise de variáveis canônicas para as fases fenológicas de folhação, floração e frutificação.

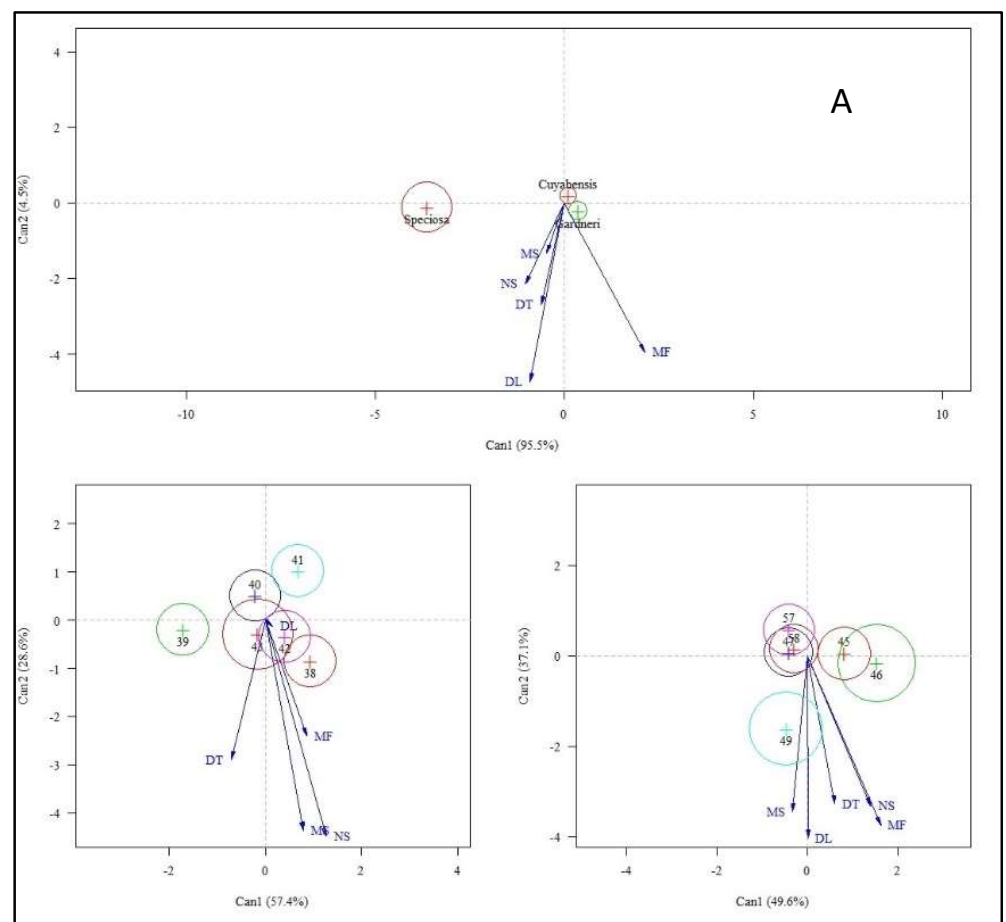

Figura 2: Dispersão gráfica de três variedades botânicas de mangabeira (var. speciosa, cuyabensis, gardneri) (A), de matrizes da subespécie cuyabensis (B) e de matrizes da subespécie gardneri (C), da Coleção de Germoplasma da EA/UFG, classificadas por análise de variáveis canônicas para as variáveis Massa do Fruto (MF), Diâmetros Transversal (DT) e Longitudinal (DL) dos frutos, Massa de Sementes (MS) e Número de Sementes (NS). 
As variedades cuyabensis e gardneri se mostraram próximas também quanto à caracterização dos frutos e sementes, enquanto speciosa foi a mais distante (Figura 2A), visto maiores valores de diâmetro longitudinal $(41,8 \mathrm{~mm})$ e transversal $(37,4 \mathrm{~mm})$, número $(14,8)$ e massa de sementes $(2,7 \mathrm{~g})$.

A massa de frutos foi maior em cuyabensis (35,8 g) e gardneri (32,8 g). As variáveis que mais diferenciaram as espécies foram à massa e o diâmetro longitudinal de frutos, representadas no gráfico com maior vetor. A avaliação de matrizes da variedade cuyabensis destacou as variáveis de massa e número de sementes (Figura 2B), enquanto os vetores no gráfico de matrizes de gardneri não foram muito distintos, um pouco maiores para massa de frutos e o diâmetro longitudinal de frutos (Figura 2C).

Quanto à avaliação de mudas às variedades foram semelhantes aos 31 DAS (Figura 3A), mas aos 67 DAS à variedade speciosa se distinguiu das demais (Figura 3B). As variáveis que mais diferenciaram as variedades foram o número de folhas e o diâmetro aos 31 DAS representadas no gráfico com maior vetor, enquanto aos 67 DAS às variáveis foram semelhantes.
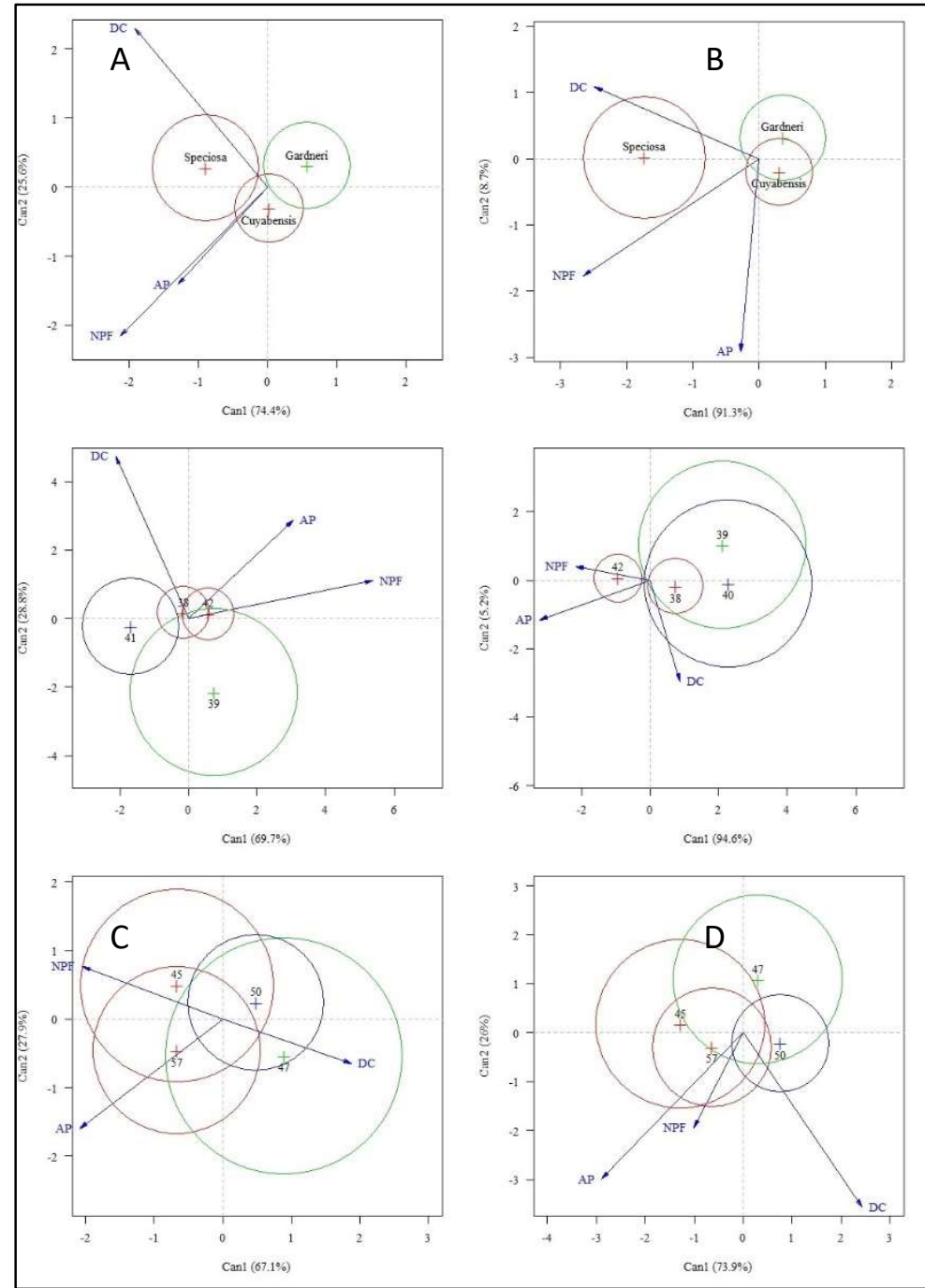

Figura 3: Dispersão gráfica do desenvolvimento inicial de mudas de três variedades botânicas de mangabeira (var. speciosa, cuyabensis, gardneri), aos 31 DAS (A) e 67 DAS (B); de mudas da variedade cuyabensis aos 31(C) e 67 DAS (D); e de mudas da variedade gardneri aos 31 (E) e 67DAS (F). Todas as plantas são da coleção de Germoplasma da EA/UFG, classificadas por análise de variáveis canônicas para as variáveis: altura de planta (AP), diâmetro do caule (DC), número de par de folhas (NPF).

As variedades speciosa e cuyabensis apresentaram maior altura $(6,0 \mathrm{~cm})$, enquanto a primeira 
também mostrou maior diâmetro $(1,8 \mathrm{~mm})$ e número de par de folhas $(3,6)$. Para a variedade cuyabensis o diâmetro foi mais determinante aos 31DAS (Figura 3C), enquanto aos 67 DAS foram o diâmetro e a altura (Figura 3D). Na variedade gardneri também houve destaque para a altura e diâmetro, mas apenas aos 67 DAS (Figura 3F).

Quanto à avaliação de mudas às variedades foram semelhantes aos 31 DAS (Figura 3A), mas aos 67 DAS à variedade speciosa se distinguiu das demais (Figura 3B). As variáveis que mais diferenciaram as variedades foram o número de folhas e o diâmetro aos 31DAS, representadas no gráfico com maior vetor, enquanto aos 67 DAS às variáveis foram semelhantes.

As variedades speciosa e cuyabensis apresentaram maior altura $(6,0 \mathrm{~cm})$, enquanto a primeira também mostrou maior diâmetro $(1,8 \mathrm{~mm})$ e número de par de folhas $(3,6)$. Para a variedade cuyabensis o diâmetro foi mais determinante aos 31DAS (Figura 3C), enquanto aos 67 DAS foram o diâmetro e a altura (Figura 3D). Na variedade gardneri também houve destaque para a altura e diâmetro, mas apenas aos 67 DAS (Figura 3F).

\section{DISCUSSÃO}

Em avaliação de população natural de H. speciosa no Cerrado (2014-2015) os botões florais foram verificados de setembro a abril, com dois picos de maior produção, em outubro e em abril, onde os indivíduos mostraram maior sincronia. Os frutos imaturos foram observados entre setembro e junho, com picos em novembro e em maio, meses de maior sincronia entre os indivíduos na fenofase.

Os frutos maduros foram encontrados no chão em maior quantidade no mês de dezembro e menor no mês de julho (ALMEIDA et al., 2018). As espécies nativas apresentam, em geral, variedade fenológica ao longo dos anos, muito influenciadas pelas características climáticas, logo a mangabeira já foi descrita também com floração de agosto a novembro, com pico em outubro (VIEIRA et al., 2017).

A floração e frutificação, bem como sua intensidade, são eventos positivamente correlacionados com a precipitação e temperatura mínima e média (ALMEIDA et al., 2018). A mangabeira pode apresentar duas produções anuais, a primeira floração ocorre de agosto a outubro, com frutos no verão, e a segunda de abril a junho, com uma menor frutificação de inverno, visto a queda de frutos influenciada pelo final do período chuvoso (SILVA JUNIOR et al., 2006; ALMEIDA et al., 2018).

O potencial de produção duas vezes por ano e a influência climática no potencial produtivo são informações importantes para direcionar a produção comercial e a formação comercial. Essas informações podem direcionar a escolha de cultivares menos afetadas pelas alterações climática, ou mesmo o melhoramento vegetal para esse fim. Ainda escolher regiões com melhor distribuição de chuvas ou optar por fontes de irrigação nos pomares, o que pode garantir produção ao longo do ano e oferta de frutos e seus subprodutos.

Ao contrário do observado para a semelhança fenológica ente as variedades cuyabensis e gardneri, estudo genético demostrou proximidade entre gardneri e pubescens, enquanto cuyabensis se mostrou mais diferente das demais (RODRIGUES, 2009). O maior potencial de floração, e consequentemente, de produção 
é característica de interesse para a produção comercial, logo a variedade speciosa se mostrou mais propicia para a formação de pomares.

A produção e as características morfológicas dos frutos apresentam grande variação em populações naturais de mangaba no Cerrado, principalmente entre populações e dentro das variedades botânicas (GANGA, 2008; PINHEIRO et al., 2018). Segundo os autores, pubescens têm frutos maiores e mais pesados, o que não pode ser verificado nesse estudo pela ausência de produção nessa variedade, no período avaliado. O diâmetro dos frutos em outros estudos foi semelhante aos aqui observados, variando de 30 a 36,4 mm (CARVALHO et al., 2003; FERREIRA et al., 2003), sendo maior em pomar cultivado do que em nativo (FERREIRA et al., 2003).

A variação no número de sementes por planta também é alta, como verificado por Lemos et al. (1989), podendo apresentar de um até dezenove em frutos por planta, coletados na Bahia. O número de sementes está relacionado com o peso do fruto (FERRO et al., 2015) logo, frutos maiores e mais pesados apresentam mais sementes, informação importante para produção de mudas da espécie ou comercialização de sementes. Ainda, o formato de frutos também é variável, em gardneri e pubescens predominam frutos redondos e verde-claros, enquanto em speciosa e cuyabensis os frutos são oblongos e de coloração amareloescura e verde-escura.

A proporção de polpa e semente nos frutos também pode variar conforme a planta matriz e a região de origem (AGUIAR FILHO et al., 1998), por exemplo, 77,00\% de polpa, 12,00\% de semente e 11,00\% de casca (NARAIN, 1990). Apesar da elevada variação fenotípica dos frutos, Vieira (2011) descreveram $42,7 \mathrm{~g}$ para a massa média dos frutos de mangaba em Goiás. Os frutos maiores e mais pesados são mais valorizados para o comércio da fruta in natura nos supermercados e feiras livres, nesse caso esse estudo apontou as variedades cuyabensis e gardneri como mais indicadas.

A elevada variabilidade da espécie também é discutida na produção de mudas, por exemplo, Ganga et al. (2009) observaram variação entre populações e dentro da população. Essa elevada variação dificulta a obtenção de uniformidade das mudas, fundamental para a sua comercialização. Ao mesmo tempo proporciona material para seleção de progênies que se destaquem quanto ao crescimento inicial, manutenção de folhas, entre outros critérios usados para o melhoramento vegetal da espécie.

\section{CONCLUSÕES}

As variedades cuyabensis e gardneri apresentam fenologias semelhantes e a variedade pubescens pode ter ausência de floração e frutificação em determinado período. O maior potencial de floração, e consequentemente, de produção torna a variedade speciosa mais propicia para a formação de pomares. Essa variedade também se mostrou mais apta para a produção de sementes.

As variedades cuyabensis e gardneri apresentarem frutos mais pesados, consequentemente mais aptos para comercialização in natura, em feiras e mercados. O desenvolvimento inicial foi diferenciado apenas para a variedade speciosa, apresentando maior altura, diâmetro e número de par de folhas. 


\section{REFERÊNCIAS}

AGOSTINI-COSTA, T. S.; SILVA, D. B.; VIEIRA, R. F.; SANO S. M.; FERREIRA, F. R. O.. Espécies de maior relevância para a região centro-oeste. In: COSTA, A. T. S.; SILVA, D. B.; VIEIRA, R. F.; SANO S. M.; FERREIRA, F. R. O.. Frutas nativas da região Centro-Oeste do Brasil. Brasília: Embrapa Recursos Genéticos e Biotecnologia, 2008. p.12-24.

AGUIAR FILHO, S. P.; BOSCO, J.; ARAÚJO, I. A.. A mangabeira (Hancornia speciosa): domesticação e técnicas de cultivo. João Pessoa: EMEPA-PB, 1998.

ALMEIDA, S. P.; PROENÇA, C. E. B.; SANO, S. M.; RIBEIRO, J. F.. Cerrado: espécies vegetais úteis. Planaltina: EMBRAPACPAC, 1998.

ALMEIRA, A. B. S.; FERREIRA, M. A. C.; BARBOSA, T. A.; SIQUEIRA, A. P. S.; SOUZA, E. R. B.. Elaboração e avaliação sensorial de sorvete diet e sem lactose de mangaba endêmica do Cerrado. Journal of Neotropical Agriculture, v.3, n.3, p.38-41, 2016.

DOI: https://doi.org/10.32404/rean.v3i3

ALMEIDA, S. E. S. S.; SILVA, P. O.; MENINO, G. C. O.; SILVA, F. G.. Fenologia de Hancornia speciosa Gomes (Apocynaceae) em Montes Claros de Goiás, Brasil. Enciclopédia Biosfera, Centro Científico Conhecer, Goiânia, v.15 n.27, 2018. DOI: http://doi.org10.18677/EnciBio 2018A91

ÁVILA, R.; OLIVEIRA, L. F.; ASCHERI, D. P. R.. Caracterização dos frutos nativos dos cerrados: araticum, baru e jatobá. Revista Agrotecnologia, v.1, n.1, p.53-69, 2010. DOI: http://doi.org/10.12971/2179-5959.v01n01a04

BIANCO, S.; PITELLI, R. A.. Fenologia de quatro espécies de frutíferas nativas dos cerrados de Selvíria, MS. Pesquisa Agropecuária Brasileira, v.21, n.11, p.1229-1232, 1986.

CARVALHO, M. O.; FONSECA, A. A. O.; SANTOS JÚNIOR, A. B.; HANSEN, D.; CASAROLI, D.; RODRIGUES, T. R.; MARTINS, A. P. B.; EVANGELISTA, A. W. P.; ALVES JÚNIOR, J.. Padrões de Chuva e de Evapotranspiração em Goiânia, GO. Revista Brasileira de Meteorologia, v.33, n.2, p.247-256, 2018. DOI: http://doi.org/10.1590/0102-7786332004

CARVALHO, M. O.; FONSECA, A. A. O.; SANTOS JÚNIOR, A. B.; HANSEN, D. S.; RIBEIRO, T. A. D.. Caracterização física, organolépticas, química e físico-química dos frutos de mangabeiras (Hancornia speciosa Gomes) da região do Conde BA. 2003.

EMBRAPA. Empresa Brasileira de Pesquisa Agropecuária. Sistema brasileiro de classificação de solos. 3 ed. Brasília: EMBRAPA, 2013.

FERREIRA, D. S.; NARAIN, N.. Caracterização química da mangaba (Hancornia speciosa Gomes) do tipo Rio Tinto em três estádios de maturação. In: SIMPÓSIO BRASILEIRO SOBRE A CULTURA DA MANGABA. Anais. Aracaju: Embrapa Tabuleiros Costeiros, 2003.

FERRO, J. H. A. A.; LEMOS, E. E. P.; FROEHLICH, A.; SOUSA, J. S.; FAUSTINO, G. L.. Caracterização morfológica dos frutos de mangaba (Hancornia speciosa Gomes) produzidos em Alagoas. Ciência Agrícola, Rio Largo, v.13, n.1, p.69-75, 2015. DOI: http://doi.org/10.28998/rca.v13i1.2054
FRANZON, R. C.. Fruteiras nativas do Cerrado têm potencial para exploração. Planaltina: Embrapa Cerrados, 2009.

FREITAS, C. V.; OLIVEIRA, P. E.. Biologia reprodutiva de Copaifera langsdorffii Desf. (Leguminosae, Caesalpinioideae). Revista Brasileira de Botânica, v.25, n.3, p.311-321, 2002. DOI: http://doi.org/10.1590/S0100$\underline{84042002000300007}$

GANGA, R. M. D.; CHAVES, L. J.; NAVES, R. V.. Parâmetros genéticos em progênies de Hancornia speciosa Gomes do Cerrado. Revista Scientia Florestalis, Piracicaba, v.37, n.84, p.395-404, 2009.

GANGA, R. M. D.. Variabilidade de plantas e progênies de populações naturais de Hancornia speciosa Gomes do Cerrado. Tese (Doutorado em Agronomia: Genética e Melhoramento de Plantas) - Universidade Federal de Goiás, Goiânia, 2008.

KÖPPEN, W.; GEIGER, R.. Klimate der Erde. Gotha: Verlag Justus Perthes, 1928.

LEMOS, R. P.; ALVES, R. E.; OLIVEIRA, E. F.; SILVA, H.; SILVA, A. Q.. Características pomológicas de mangabeiras (Hancornia speciosa Gomez) da Paraíba. In: CONGRESSO BRASILEIRO DE FRUTICULTURA, 10. Anais. Fortaleza: SBF, 1989. p.346-351.

MITTERMEIER, R. A.; FONSECA, G. A. B.; RYLANDS, A. B.; MITTERMEIER, C. G.. Megadiversity: earth's biologically wealthiest nations. México: CEMEX, 1997. p.39-49.

MONACHINO, J.. A revision of Hancornia (Apocynaceae). Lilloa, Tucumán, v.11, p.19-48, 1945.

NARAIN, N.. Mangaba. In: NAGY, S.; SHAW, P. E.; WADORWSKI, W.. Fruits of tropical and subtropical origin. Composition, properties and uses. Lake Alfred: FSS, 1990. p.159-165.

NUNES, G. H. C.; SILVA, S. M. C.; PIRES, L. L.; NAVES, R. V.; LEONARDO, B. R. L.. Fenologia e caracterização de plantas de Hancornia speciosa da coleção da EA/UFG. In: REUNIÃO DA SOCIEDADE BRASILEIRA PARA O PROGRESSO DA CIÊNCIA, 63. Anais. Goiânia: Coonpex, 2011.

PINHEIRO, E. A.; COIMBRA, R. R.; SILVA, K. L. F.; FERREIRA, W. M.. Characterization and phenotypic variability in natural populations of mangabeira in the state of Tocantins, Brazil. Revista Caatinga, Mossoró, v.31, n.3, p.560-571, 2018. DOI: http://doi.org/10.1590/1983-21252018v31n304rc

R CORE TEAM. R: A language and environment for statistical computing. Vienna: R Foundation for Statistical Computing, 2019.

RIBEIRO, J. F; CASTRO, L. H. R.. Método quantitativo para avaliar características fenológicas em árvores. Revista Brasileira de Botânica, v.9, n.1, p.7-11, 1986.

RODRIGUES, J. L.. Desenvolvimento e caracterização de marcadores microssatélites e estrutura genética de populações naturais de Hancornia speciosa Gomes 
(Apocynaceae). Tese (Doutorado em Agronomia: Genética e Melhoramento de Plantas) - Universidade Federal de Goiás, Goiânia, 2009.

SILVA JUNIOR, F.; LÊDO, A. S.. Botânica. In: SILVA JUNIOR, F.; LÊDO, A. S.. A cultura da mangaba. Aracaju: Embrapa Tabuleiros Costeiros, 2006.

SILVA, S. M. C.; NASCIMENTO, J. L.; NAVES, R. V.. Produção da Mangabeira (Hancornia speciosa Gomes) irrigada e adubada nas condições do estado de Goiás. Bioscience Journal, v.22, n.2, 2006.

SOARES, F. P.; RAÍRYS, R. P.; NOGUEIRA, C.; OLIVEIRA, L. M.; SILVA, D. R. G.; PAIVA, P. D. O.. Cultura da mangabeira (Hancornia speciosa Gomes). Boletim Agropecuário, Lavras, n.67, p.1-12, 2007.

SOARES, L. V.; MELO, R.; OLIVEIRA, W. S.; SOUZA, P. M.; SCHMIELE, M.. Brazilian Cerrado fruits and their potential use in bakery products. In: LEWIS, H.. Bread: Consumption, cultural significance and health effects. New York: Nova Publisher, 2017. p.125-160.

VIEIRA NETO, R. D.; CINTRA, F. L. D.; SILVA, A. L.; SILVA JÚNIOR, J. F.; COSTA, J. L. S.; SILVA, A. A. G.; CUENCA, M. A. G.. Sistema de produção de mangaba para os tabuleiros costeiros e baixada litorânea. Aracaju: Embrapa, 2002.

VIEIRA, M. C.. Caracterização de frutos e de mudas de mangaba (Hancornia speciosa Gomez) de Goiás.

Dissertação (Mestrado em Agronomia) - Universidade Federal de Goiás, Goiânia, 2011.

VIEIRA, M. C.; SOUZA, E. R. B.; PAULA, M. S. P.; NAVES, R. V.; SILVA, G. D.. Mangabeira (Hancornia speciosa Gomes): uma frutífera promissora do Brasil. Scientific Electronic Archives, v.10, n.2, p.45-55, 2017.

VIEIRA, R. F.; COSTA, T. S. A.; SILVA, D. B.; SANO, S. M.; FERREIRA, F. R.. Frutas nativas da região Centro-Oeste do Brasil. Brasília: Embrapa Informação Tecnológica, 2010.

A CBPC - Companhia Brasileira de Produção Científica (CNPJ: 11.221.422/0001-03) detém os direitos materiais desta publicação. Os direitos referem-se à publicação do trabalho em qualquer parte do mundo, incluindo os direitos às renovações, expansões e disseminações da contribuição, bem como outros direitos subsidiários. Todos os trabalhos publicados eletronicamente poderão posteriormente ser publicados em coletâneas impressas sob coordenação da Sustenere Publishing, da Companhia Brasileira de Produção Científica e seus parceiros autorizados. Os (as) autores (as) preservam os direitos autorais, mas não têm permissão para a publicação da contribuição em outro meio, impresso ou digital, em português ou em tradução. 